\title{
Intraoral Endoscopic Approach for Treatment of Condylar Fractures of the Mandible
}

\author{
Frank Wilde
}

\subsection{Introduction}

The literature is replete with techniques regarding the open reduction and fixation of the condylar fractures of the mandible. The extraoral approach is preferred by the majority of surgeons in comparison to the intraoral approach. Nevertheless, open reduction and internal fixation by an extraoral approach has the evident risk to cause transient or even permanent facial nerve injury [1-4], leads inevitably to a facial scar $[1,5]$, and can course salivary fistulas, sialoceles $[1,6]$, Frey syndrome, or disturbance of the great auricular nerve [1]. In contrast, an intraoral approach is minimizing these abovementioned risks and facial scars can be avoided in general $[7,8]$.

Silverman in 1925 was the first person to mention about the intraoral approach to condylar fractures [9]. However, at that time, the surgeons were facing several difficulties treating those fractures due to a lack of adequate instruments. Fritzemeier and Bechthold developed the 90-degree angular screwdriver, and it served as a milestone in the intraoral management of condylar neck fractures. In their study, there were 32 fractures of which 2 cases showed early failures. Other cases during follow-up showed minor deviation from axis, but there were no evident problems in the temporomandibular joint function [10].

Based thereupon, several authors were reporting about the use of an intraoral approach treating condylar fractures surgically. Forty-eight cases of displaced and shortened mandibular condyle fractures were treated by an intraoral approach and studied by Mokros and Erle in 1996. In 2/3 of the treated fractures, the reduction was successful, and no

\footnotetext{
F. Wilde $(\square)$

Department of Oral and Plastic Maxillofacial Surgery,

Armed Forces Hospital, Ulm, Germany

Department of Oral and Maxillofacial Surgery,

University Hospital, Ulm, Germany

e-mail: frank.wilde@uni-ulm.de
}

significant complications were noted in the intraoperative or postoperative period.

TMJ function was good in $90 \%$ of the patients, $43 \%$ were free of symptoms, and $47 \%$ had minor dysfunction. The authors came to the result that proper reduction of the bone fragments is most important for therapeutic success [11].

Schön et al. [8] compared in a study an intraoral endoscopy-assisted approach with an extraoral approach for the treatment of condylar fractures. A reduced risk of facial nerve damage and no visible scars were the major conclusion of the study, and they also opined that intraoral endoscopic approach is a reliable technique for treating condylar fractures [8]. Veras et al. [12] were looking in their study on 25 patients with condylar fractures which were treated surgically by an intraoral approach. The mean mouth opening postoperatively was $4.8 \mathrm{~cm}$. Patients postoperatively did not have clicking of the joint, facial nerve weakness, or pain of the muscles or the joint. They opined that intraoral reduction allowed the anatomic ramus height to be restored and that the functional results were acceptable [12].

Other authors like Jensen et al. [13] or Schneider et al. [14] were not so enthusiastic about the outcome of surgicaltreated condylar fractures employing an intraoral approach $[13,14]$. Jensen et al. in 2006 stressed on the fact that intraoral approach for the condylar fractures is very technically demanding and there is a chance of getting postoperative complications [13]. Schneider et al. [14] compared in a retrospective study 21 fractures which were treated with an intraoral approach with 24 fractures which were reduced by an extraoral perimandibular approach. In their study, the cases treated by intraoral approach showed suboptimal radiologic findings, and the patients' subjective feelings pointed to less favorable clinical results. They put forward the suggestion that fractures which do not require extensive manipulation and fractures which can be reduced exactly under a limited view only should be approached intraorally. For all other fractures, they recommend extraoral approaches [14]. 


\subsection{Surgical Technique}

From the authors' experience, fractures of the condylar base and the low and medial part of the condylar process can be addressed typically by the following described technique. Treating high condylar neck fractures is demanding and requires experience in using such an approach. Fractures of the condylar head or the transition zone between the neck and head cannot be reached with this approach, and extraoral incisions are still required when this kind of fractures is getting treated surgically.

For the below-described technique, a team of three surgeons (one leading surgeon and two assistant surgeons) are highly recommended.

\subsubsection{Special Surgical Instruments and Devices}

To facilitate open reduction and internal fixation of condylar fractures via an intraoral approach with predictable results, special equipment is mandatory.

The most important instruments are a $90^{\circ}$ angled screwdriver and drill (Fig. 54.1a). The screwdriver should have necessarily a sliding screw-holder which facilitates to hold the screw and plate together (Fig. 54.1b), because positioning a plate with one hand and fixing the screw with the other hand is not appropriate and will lead to unsuccessful procedures. Self-retaining screwdriver-bits or even selftapping screws should be avoided as well. The authors recommend a straight $90^{\circ}$ angled screwdriver with the aforementioned sliding screw-holder and centric-positioned screwdriver-bits. Screwdrivers with eccentric-positioned screwdriver-bits show a lower height indeed.
However, they will lead to tilting of the screwdriver during the activation of the device, which results in an inadequate transfer of the force and a frequent loosening of the screws from the bit.

Besides the $90^{\circ}$ angled screwdriver and drill, extra-long instruments in the form of raspatories and reposition hooks have to be recommended insistently (Fig. 54.2). They simplify the manipulation and reduction of the fractured condyle with a good direct view into the operation site. Using standard configurated instruments results in less vision due to obstructing the view by the operator's hands.

An appropriate light-intensive headlight is necessary for proper illumination of the operation site (Fig. 54.3).

A $4 \mathrm{~mm}$ caliber $30^{\circ}$ angled endoscope has to be recommended as well. In combination with a special retractor in which the endoscope can be inserted, a good visualization, especially of the posterior border of the ramus, can be achieved (Fig. 54.4).

In addition, a special retractor with a fiber-optic light guide which can be positioned buccally to the posterior border of the ramus enables good illumination of the surgical site (Fig. 54.5). Nevertheless, having an appropriate headlight, this instrument seems to be dispensable.

It can be further useful to fix the patient during surgery in a Mayfield head clamp as it is commonly used by the neurosurgeons. This allows traction with the retractors without any movement of the head.

Besides the described instruments, there are several special instruments and devices available on the market to facilitate open reduction and internal fixation using an intraoral approach. However, from the authors' experience, the aforementioned instruments and devices are the most helpful in treating condylar fractures by an intraoral approach.
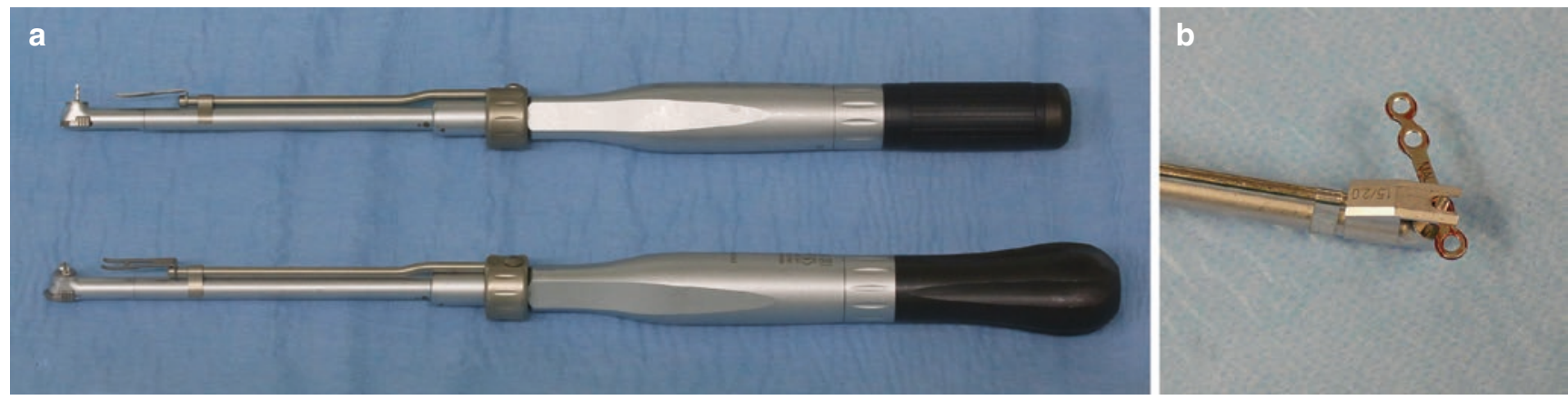

CAssociation of Oral and Maxillofacial Surgeons of India

Fig. 54.1 (a) $90^{\circ}$ angled screwdriver and drill. (b) Sliding screw-holder which facilitates to hold the screw and plate together (Medartis, Basel, Switzerland) 


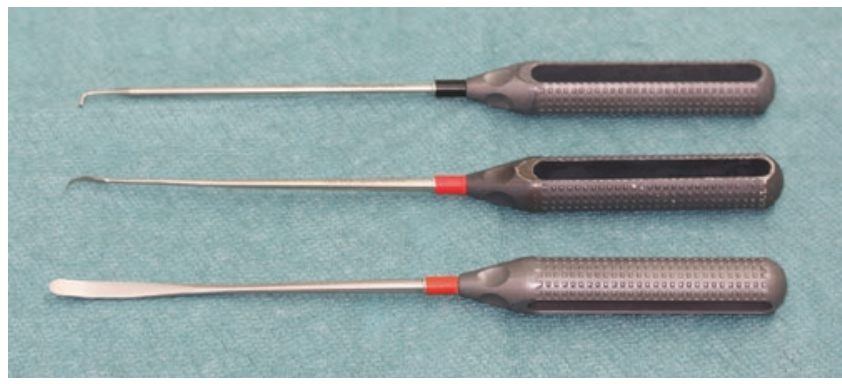

CAssociation of Oral and Maxillofacial Surgeons of India

Fig. 54.2 Extra-long instruments in the form of raspatories and reposition hooks (Karl Storz, Tuttlingen, Germany)

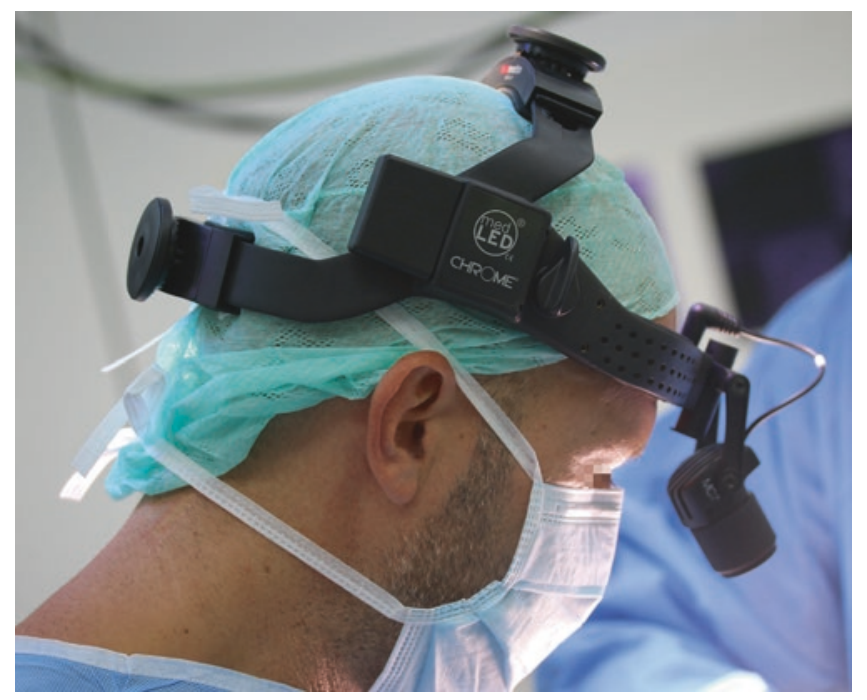

CAssociation of Oral and Maxillofacial Surgeons of India

Fig. 54.3 LED headlight (KLS Martin, Tuttlingen, Germany)

\subsubsection{Surgical Access}

By extending the standard vestibular incision in a superior direction along the ascending ramus, the ramus and the condyle region can be exposed intraorally (Fig. 54.6). The approach is following Obwegeser's principles of avoiding visible scars by extending his approach to the mandibular ramus for sagittal split osteotomy. During the incision of the oral mucosa, the anatomical course of the buccal nerve has to be taken into account. The dissection of the mucoperiosteal flap starts from the mandibular corpus in the region of the first molar to mandibular angle and far up to the condyle until the facture line can be explored. To get an appropriate
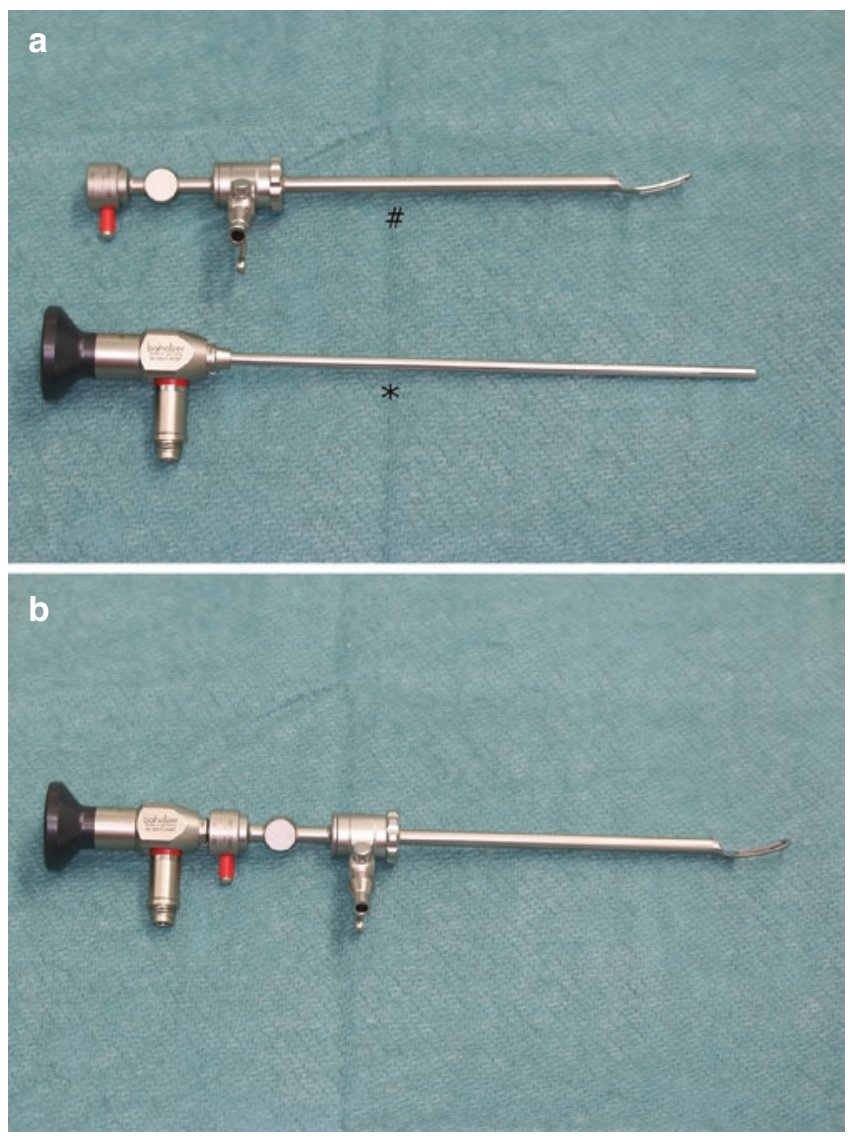

CAssociation of Oral and Maxillofacial Surgeons of India

Fig. 54.4 (a) $4 \mathrm{~mm}$ caliber $30^{\circ}$ angled endoscope (asterisk) and retractor in which the endoscope can be inserted (hash symbol). (b) Retractor with inserted endoscope (Karl Storz, Tuttlingen, Germany)

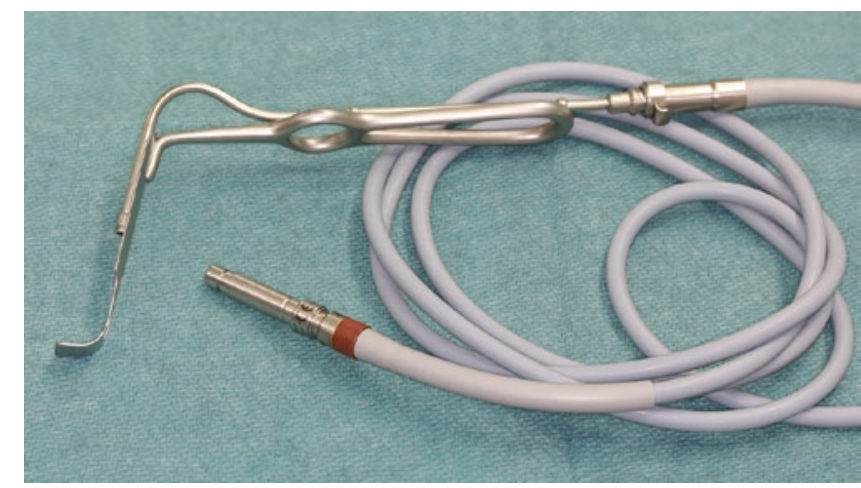

CAssociation of Oral and Maxillofacial Surgeons of India

Fig. 54.5 Retractor with a fiber-optic light guide (Karl Storz, Tuttlingen, Germany) 


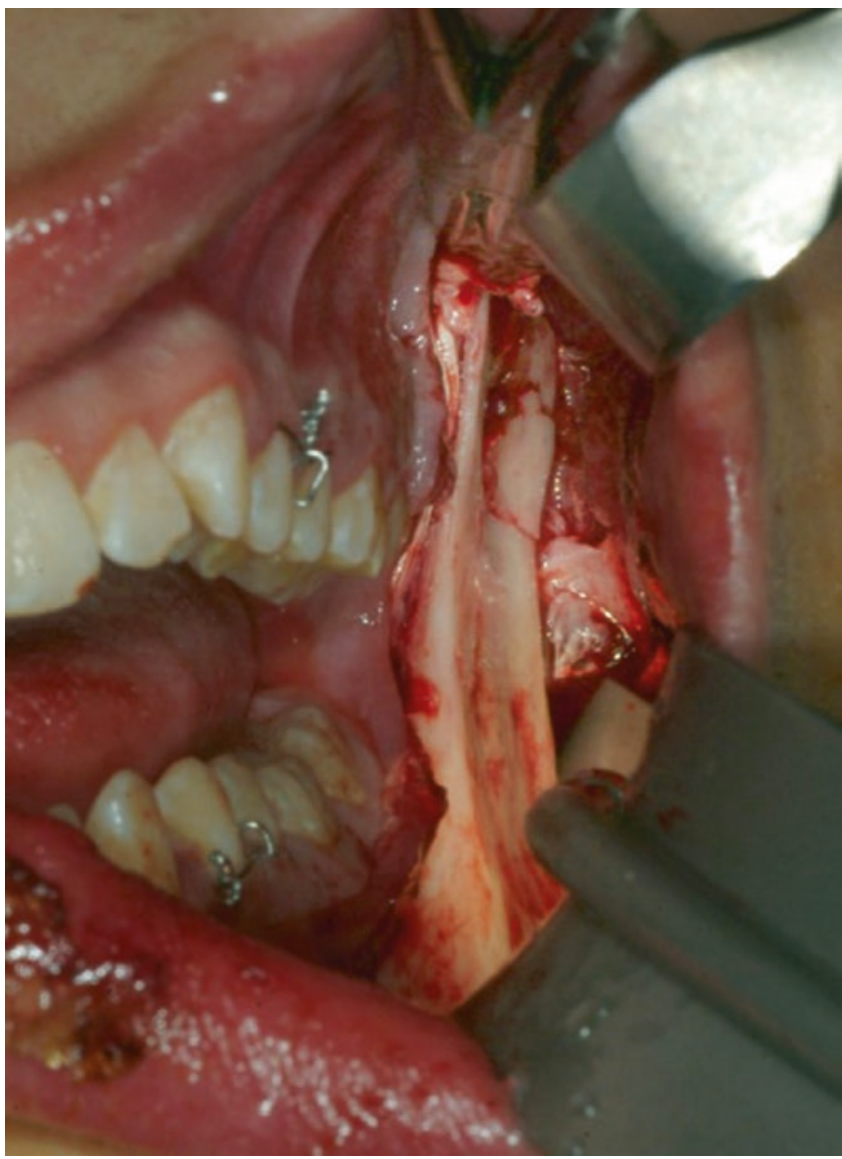

CAssociation of Oral and Maxillofacial Surgeons of India

Fig. 54.6 Intraoral approach to the condyle region by extending the standard vestibular incision in a superior direction up the ascending ramus

visualization of the condylar neck region, the mucosa including the fibers of the temporal muscle had to striped from the coronoid process up to or even higher than the mandibular notch. During dissecting the posterior border of the mandibular ramus, the retromandibular vein has to be taken under consideration. Coagulation in this region has to be done carefully, due to the anatomical proximity to the facial nerve which is running laterally in the parotid gland. This is the region where the facial nerve may be damaged during the procedure. In addition to coagulation, vigorous traction can damage the facial nerve in this location as well.

\subsubsection{Surgical Procedure}

After dissection to get sufficient access to the condylar neck region, the displaced condyle has to be identified. The best instrument for this is the extra-long raspatorium depicted in Fig. 54.2. During this procedure, the ramus has to be distracted. This can be performed by pulling the mandible caudally by hand. Another option is to fix one mini-screw in the

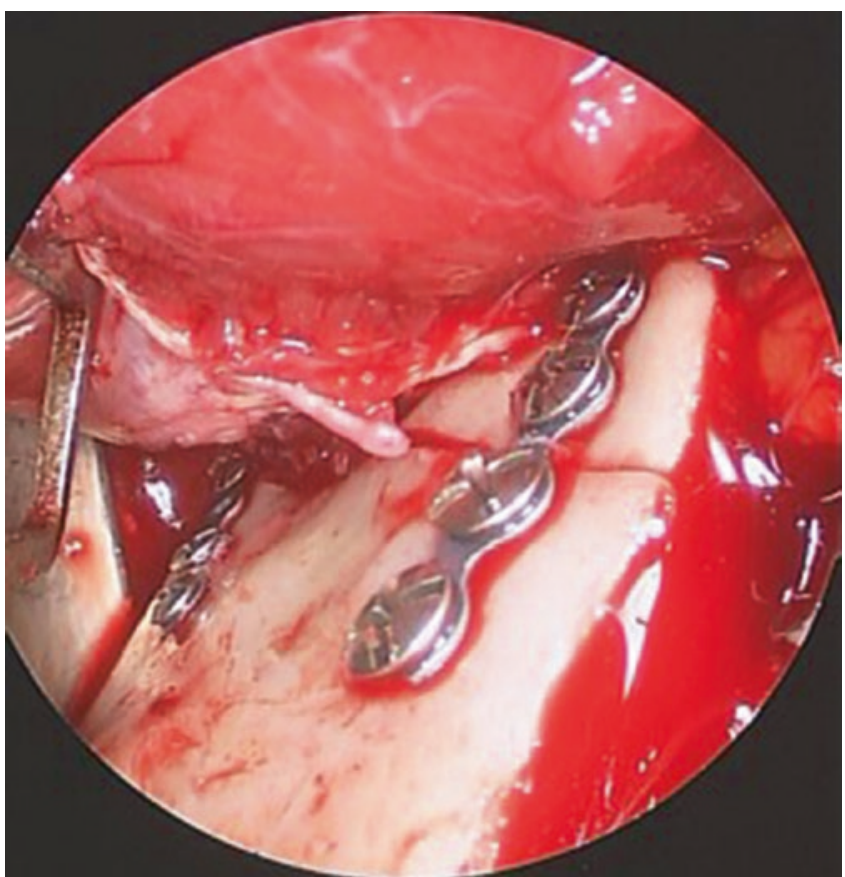

CAssociation of Oral and Maxillofacial Surgeons of India

Fig. 54.7 After temporary osteotomy and re-fixation of the coronoid process to get better access for repositioning of medial displaced condyle

mandibular angle to twist a wire around, which is diverted out of the skin in the mandibular angle region by a stab incision. However, this leads to a small extraoral scar.

For this maneuver, a full relaxation of the patient by the anesthesiologist is recommended. Due to the very low risk for facial nerve damage employing this approach, this can be done without increasing this risk.

For medial displaced condyles in high condylar neck fractures, it is sometimes helpful to perform a temporary osteotomy of the coronoid process to get better access for repositioning. A later re-fixation of the osteomized coronoid process by a miniplate is in theory not needed but recommended by the authors (Fig. 54.7).

Once the dislocated fragment is identified, it has to be repositioned anatomically. MMF cannot be recommended in all cases. In some cases, it can be helpful to get a stable reduction during osteosynthesis; however, in most cases, MMF is not very helpful. This decision has to be made individually case by case.

In most cases, the reposition of the proximal fragment is not stable from the beginning (Fig. 54.8). Therefore, the authors recommend to drill the first screw hole in the condyle fragment close to the fracture line in the region of the sigmoid notch. A four- or five-hole $1.0 \mathrm{~mm}$ up to 1.2 -mm-thick miniplate is fixed in this hole with a 5- to 6-mm-long screw with a diameter of $2.0 \mathrm{~mm}$. The screw should not be tightened completely. Then the reduction of condyle fragment 


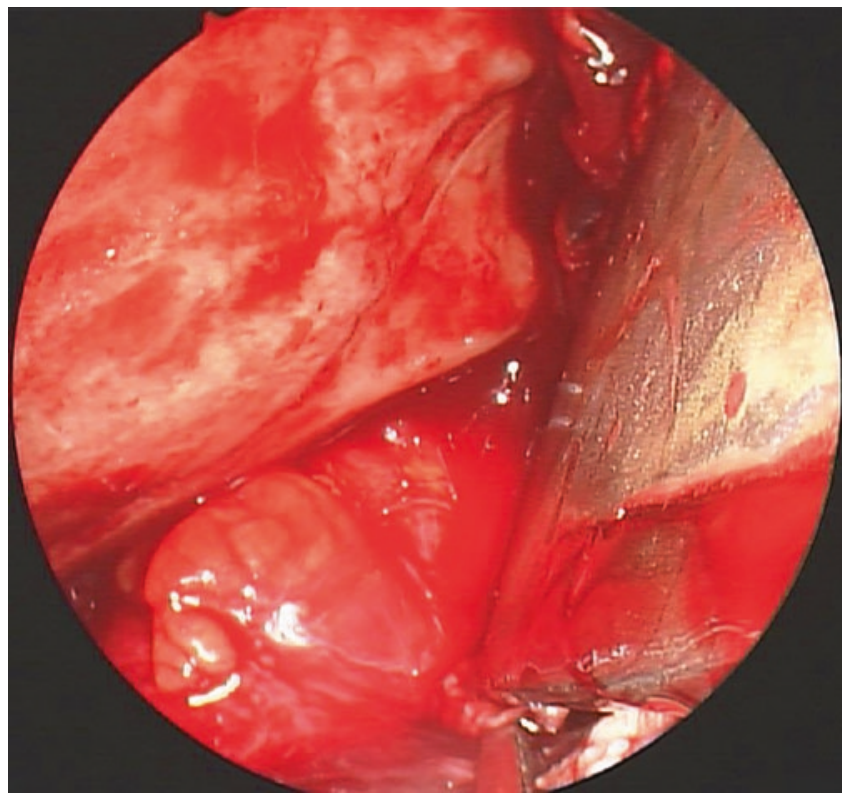

CAssociation of Oral and Maxillofacial Surgeons of India

Fig. 54.8 Endoscopic view after repositioning of a condylar neck fracture

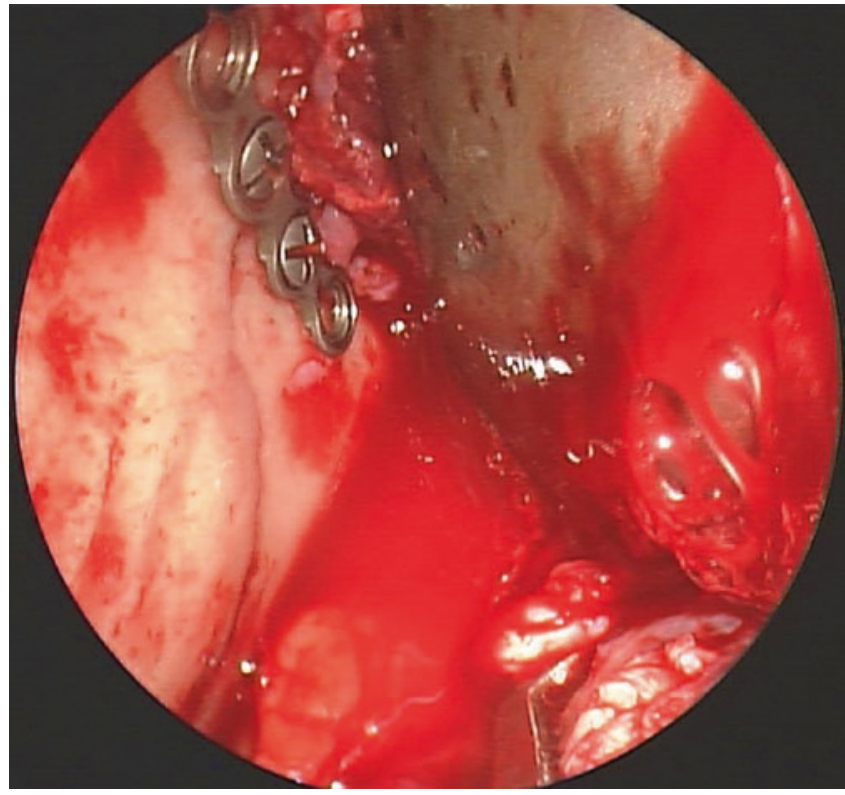

CAssociation of Oral and Maxillofacial Surgeons of India

Fig. 54.9 Endoscopic view after fixation of a four-hole miniplate close to the sigmoid notch with two screws adjacent to the fracture line

can be achieved by pulling on the miniplate with one of the extra-long reposition hooks. By visual control of the repositioned fragment, the miniplate should now be fixed in the ramus part of the fracture close to the sigmoid notch by eccentric drilling of the screw hole for fracture line compression during screw insertion. After fixing the second screw, the first screw has to be tightened completely (Fig. 54.9).

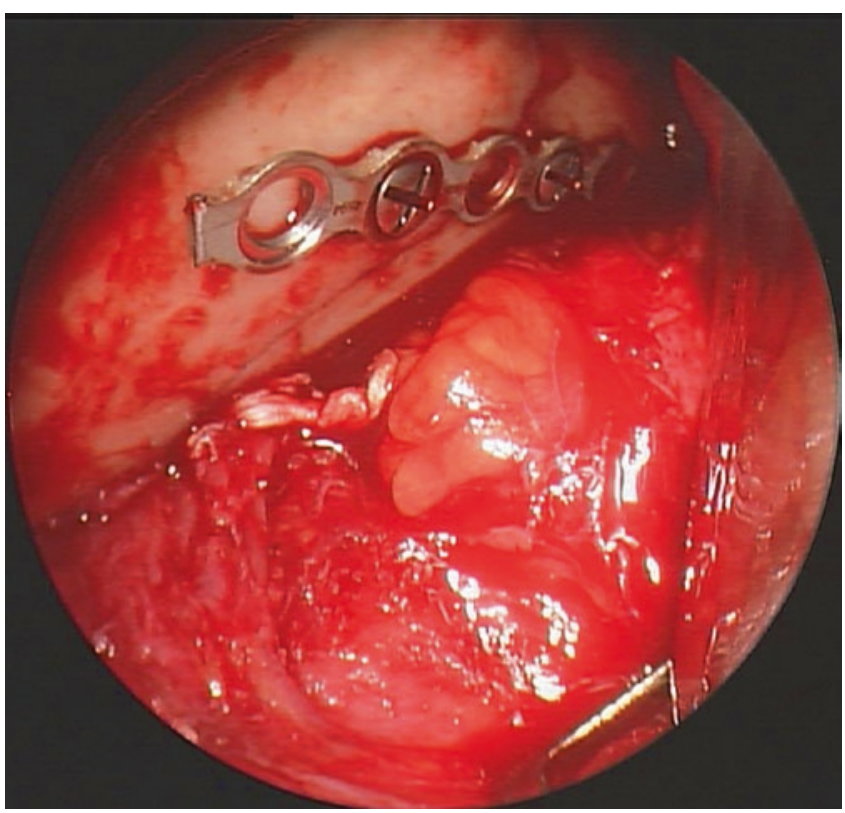

(C)Association of Oral and Maxillofacial Surgeons of India

Fig. 54.10 Endoscopic view after fixation of a five-hole miniplate at posterior border with two screws adjacent to the fracture line

Once this is facilitated, often a small gap and flaring can be identified at the posterior border of the condylar neck. To close this gap, a second four- to five-hole miniplate has to be fixed at the posterior border of the condylar neck. Here also the hole has to be drilled in the condyle fragment close to the fracture line. First, the plate has to be fixed in this hole and should be aligned along the posterior border of the condylar neck respectively the ramus. Again, the screw should not be tightened completely at this stage. After exact anatomical reposition of the condyle, the next screw is now drilled for compression osteosynthesis in the ramus part of the ramus close the fracture line and immediately fixed with the fourth screw (Fig. 54.10). The third screw is then tightened completely to stabilize the fracture. After attaining control of the anatomical correct reposition with the endoscope or in low condylar neck fractures even with a simple dental mirror, the other screw holes in both plates are drilled and fixed, starting with the plate at the posterior border and ending with plate close to the sigmoid notch. Figure 54.11 shows the final endoscopic view with the two plates fixed. Figure 54.12 is illustrating the recommended sequencing of plate and screw positioning to facilitate open reduction and internal fixation via an intraoral approach using two miniplates.

In addition, the authors recommend intraoperative imaging with a 3D C-arm device at the end of the procedure when available (Fig. 54.13). This allows the intraoperative radiologic control and documentation of the reduced fracture and of the position of the plates in a multiplanar view and enables an immediate intraoperative correction when the result of the 


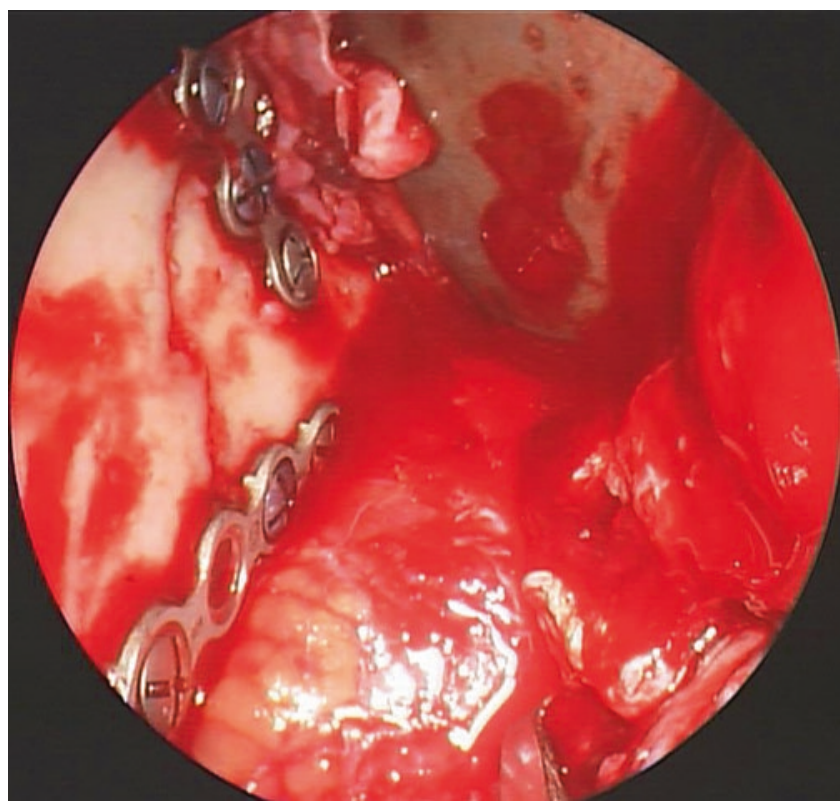

CAssociation of Oral and Maxillofacial Surgeons of India

Fig. 54.11 Endoscopic view after complete fixation of a condylar neck fracture with two miniplates. One four-hole plate in the region of the sigmoid notch and a second five-hole miniplate at posterior border

procedure is not satisfactory. This reduces the risk for revision surgeries considerably $[15,16]$.

When the result is satisfactory, the intraoral mucosa has to be closed in the standard way like every intraoral incision.

Even when the fracture is reduced and stabilized with success, the authors still recommend a light MMF with elastics strained over two or four MMF screws or arch bars for approximately 1 week for slight immobilization and guidance into the proper occlusion. In case of a postoperative insufficient occlusion, a prolonged functional treatment as in nonsurgical treated condylar fractures with elastics or an orthodontic device like an activator or bionator has to be recommended.

\subsubsection{Osteosynthesis Material}

As mentioned before, the author is recommending the usage of two miniplates. The plate at the posterior border is responsible for the stability primarily, whereas the plate in the region of the sigmoid notch prevents flaring of the distal fragment during function additionally.

For osteosynthesis, $1.0-\mathrm{mm}$ up to 1.2 -mm-thick miniplates can be recommended (Fig. 54.14). It can be favorable to use $1.2-\mathrm{mm}$-thick miniplates at the posterior border due to stability reasons. The screws should be usually 5-6 mm long with a diameter of $2.0 \mathrm{~mm}$. Locking screws

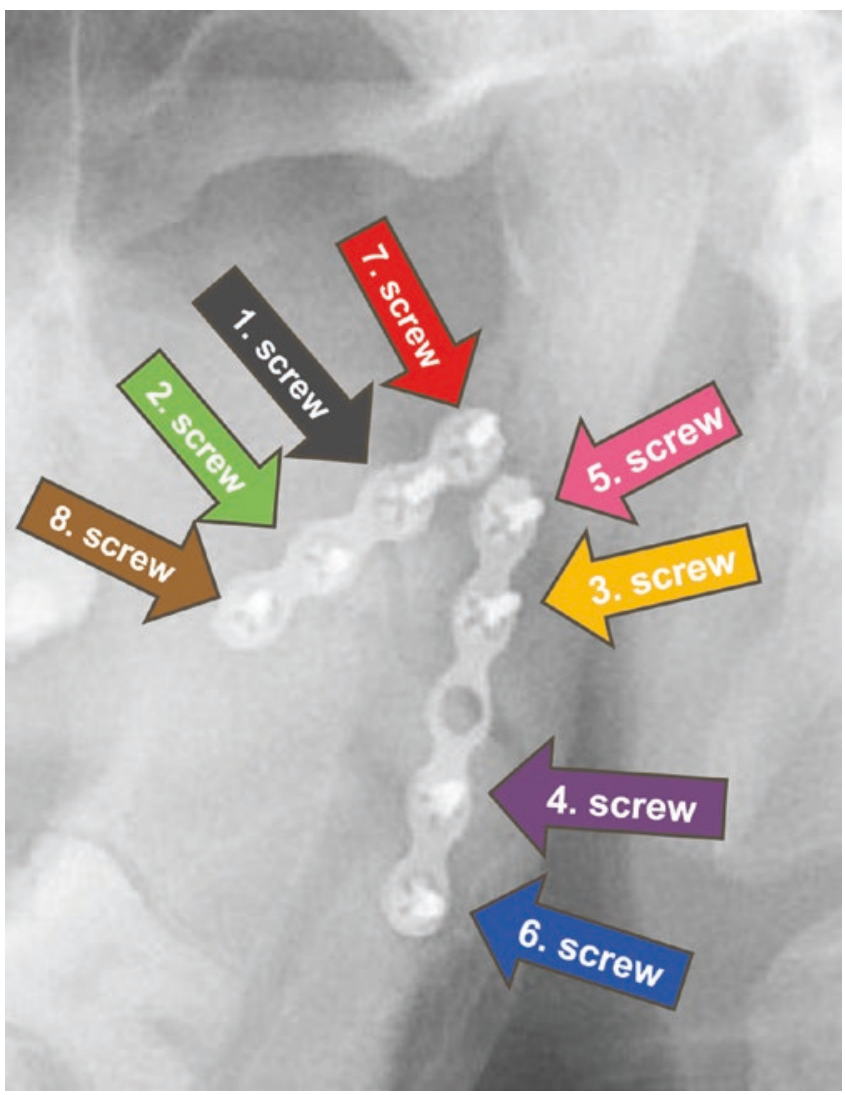

CAssociation of Oral and Maxillofacial Surgeons of India

Fig. 54.12 Recommended sequencing of plate and screw positioning to facilitate open reduction and internal fixation via an intraoral approach using two miniplates

are not necessary and should never be used for the screw holes which are adjacent to the facture line. These holes should be drilled eccentric to achieve compression at the facture line. In modern osteosynthesis systems, locking and non-locking screws can be used with the same plates. Using such a system, it may be advantageous to use locking screws for the fracture-distant screw holes. Nevertheless, as mentioned before, locking screws are not needed in this technique.

Besides standard miniplates, there is the option for the use of so-called 3D plates or special designed condylar neck plates (Fig. 54.15). However, from the authors' experience, plating with two miniplates enables the aforementioned successive repositioning and fixation of the facture most easily and leads to sufficient stability.

There are new developments of anatomically preformed 3D condylar neck plates with integrated reposition wings for the posterior border and the sigmoid notch (Fig. 54.16). Whether these kinds of plates are beneficial or not has to be investigated in the future. 

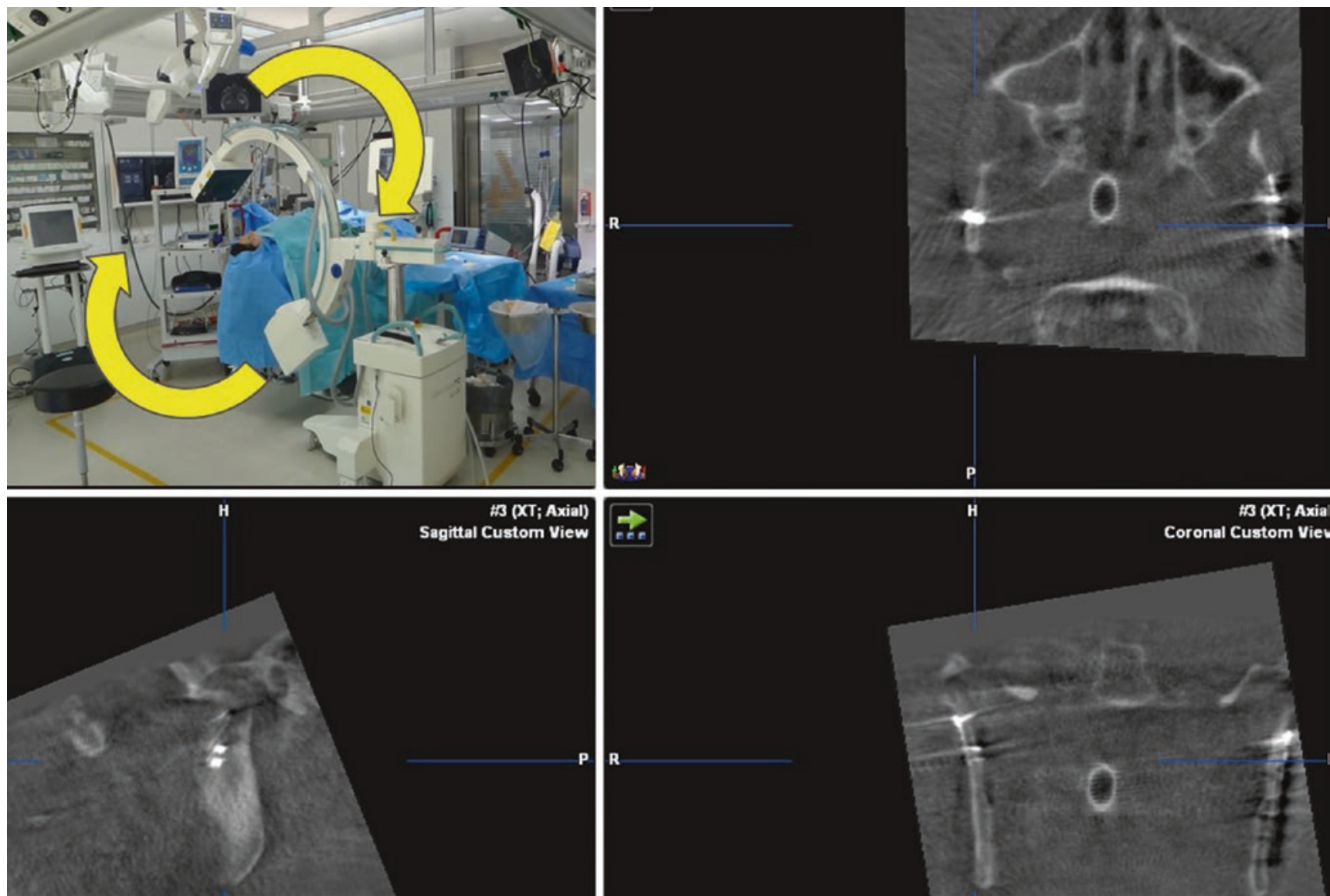

CAssociation of Oral and Maxillofacial Surgeons of India

Fig. 54.13 Intraoperative imaging with a 3D C-arm device (Ziehm, Erlangen, Germany) at the end of the procedure and multiplanar view of the surgical result

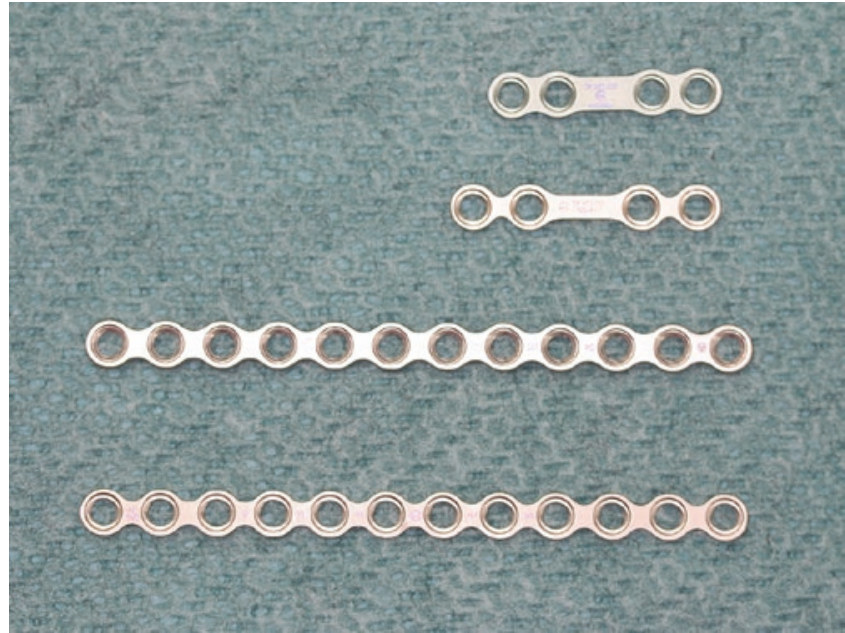

CAssociation of Oral and Maxillofacial Surgeons of India

Fig. $\quad 54.14 \quad 1.0-\mathrm{mm}$ and $1.2-\mathrm{mm}$-thick standard miniplates (DePuySynthes, Zuchwil, Switzerland)

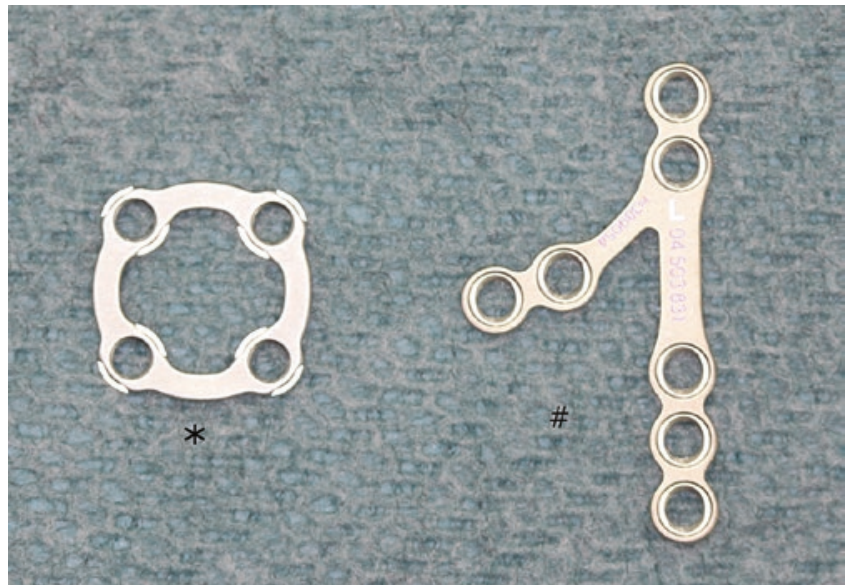

CAssociation of Oral and Maxillofacial Surgeons of India

Fig. 54.15 3D miniplate (asterisk) and special condylar neck plate (hash symbol) (DePuySynthes, Zuchwil, Switzerland) 

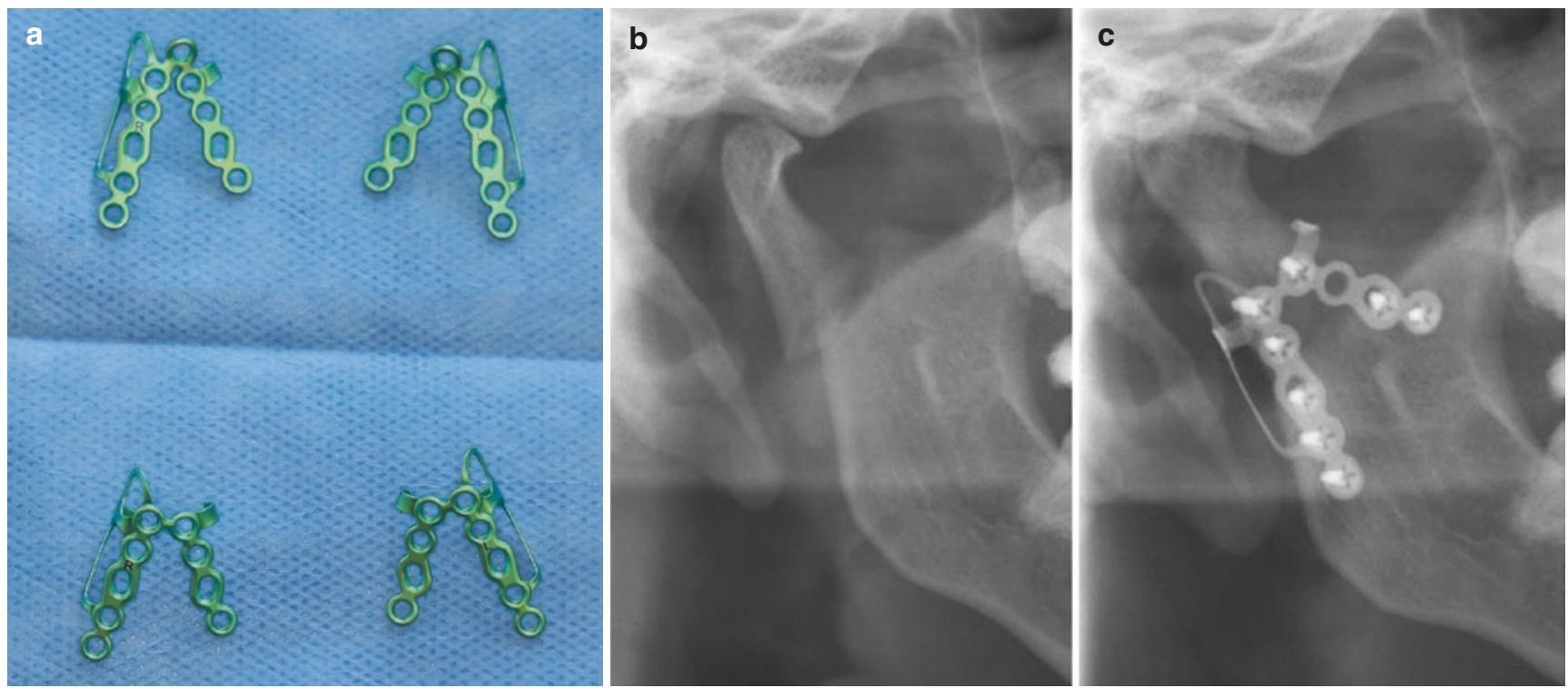

CAssociation of Oral and Maxillofacial Surgeons of India

Fig. 54.16 (a) Anatomically preformed 3D condylar neck plates with integrated reposition wings for the posterior border and the sigmoid notch (KLS Martin, Tuttlingen, Germany). (b) Displaced right condylar neck fracture. (c) Condylar neck fracture after repositioning and fixation employing an intraoral approach

\subsection{Complications}

There is no much difference in complications by treating condylar factures via an intraoral approach in comparison to all other treatment options. Postoperative infection is the most common complication followed by malocclusion. Dysfunctional degeneration of the injured joint can lead to joint clicking, pain, reduced mouth opening, and mandibular deviation during opening and closing. Even severe arthritis or condylar resorption can occur up to the total destruction or loss of the joint. Hardware failure in form of plate fractures or loosening of screws can be seen occasionally as well.

In addition to the avoidance of any visible extraoral scar, the biggest advantage in comparison to all extraoral approaches for surgical treatment of condylar fractures is the very low complication rate concerning facial nerve injuries, salivary fistulas, sialoceles, Frey syndrome, or disturbance of the great auricular nerve.

\subsection{Conclusion}

The described intraoral approach for the treatment of condylar fractures is favorable for fractures of the condylar base and the condylar process. The biggest benefit and advantage in comparison to all extraoral approaches is the very low complication rate concerning facial nerve injuries and the
Table 54.1 Advantages and disadvantages of an intraoral approach for the treatment of condylar fractures

Advantages

- No visible scars

- Very low risk for facial nerve damaging

- Very low risk for salivary fistulas, sialoceles or Frey syndrome

- No risk for disturbance of the great auricular nerve

Disadvantages

- Need for special equipment

- Technically demanding

- Not suitable for condylar head fractures

avoidance of extraoral scars. A disadvantage is the need for special equipment to facilitate this technically demanding procedure with regular success (Table 54.1).

\subsection{Case Scenario}

History: A 24-year-old female with history of a bicycle accident.

Clinical features: Malocclusion with lateral open bite left. Limited and painful mouth opening. Mobile mandible paramedian region left. Chin hematoma.

Diagnosis: Medial displaced condylar process fracture right and slightly displaced paramedian fracture left (Fig. 54.17a-b). 

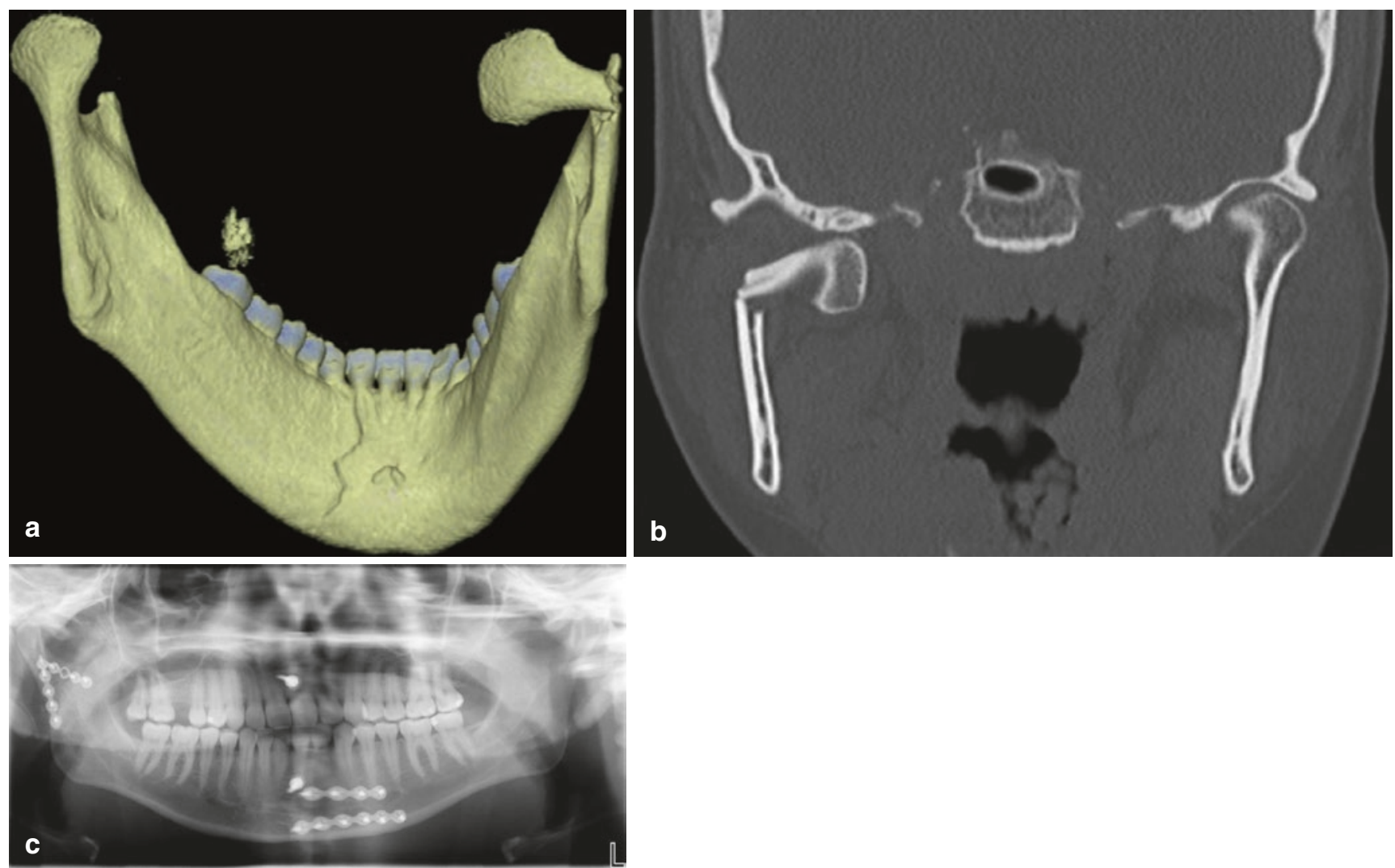

CAssociation of Oral and Maxillofacial Surgeons of India

Fig. 54.17 (a) 3D reconstruction of the preoperative CT scan showing the medial displaced condylar process fracture right and slightly displaced paramedian fracture left. (b) Coronal view of the preoperative CT scan showing the medial out of the fossa displaced condylar process

Surgical plan: Open reduction and internal fixation of both fractures employing an intraoral approach. The paramedian fracture should be fixed first with two miniplates. A gap of the lingual cortex should be prevented by compression of the mandible in the posterior region and overbending the plates. The condylar neck fracture should be fixed second with two miniplates as well.

Postoperative findings: Sufficient reduced and stabilized fractures at the condylar process right and paramedian left (Fig. 54.17c). Proper occlusion and regular mouth opening 4 weeks after surgery without any deviation during function.

\section{References}

1. Rozeboom AVJ, Dubois L, Bos RRM, Spijker R, de Lange J. Open treatment of condylar fractures via extraoral approaches: A review of complications. J Craniomaxillofac Surg. 2018;46(8):1232-40. fracture right. (c) Postoperative panoramic X-ray showing well-sufficient reduced and with miniplates stabilized fractures paramedian left and at the condylar process right

2. Vural E. Treatment of adult subcondylar mandibular fractures: closed vs open vs endoscopic approach. Arch Otolaryngol Head Neck Surg. 2004;130(10):1228-30.

3. Hall MB. Condylar fractures: surgical management. J Oral Maxillofac Surg. 1994;52(11):1189-92.

4. Ellis E 3rd, Dean J. Rigid fixation of mandibular condyle fractures. Oral Surg Oral Med Oral Pathol. 1993;76(1):6-15.

5. Haug RH, Assael LA. Outcomes of open versus closed treatment of mandibular subcondylar fractures. J Oral Maxillofac Surg. 2001;59(4):370-5. Discussion 375-6

6. Vogt A, Roser M, Weingart D. Transparotidean approach to surgical management of condylar neck fractures. A prospective study. Mund Kiefer Gesichtschir. 2005;9(4):246-50 [Article in German].

7. Patil RS, Gudi SS. Management of subcondylar fracture through intraoral approach with rigid internal fixation. J Maxillofac Oral Surg. 2011;10(3):209-15.

8. Schön R, Gutwald R, Schramm A, Gellrich NC, Schmelzeisen R. Endoscopy-assisted open treatment of condylar fractures of the mandible: extraoral vs intraoral approach. Int J Oral Maxillofac Surg. 2002;31(3):237-43.

9. Silverman SL. A new operation for displaced fractures at the neck of the mandibular condyle. Dental Cosmos. 1925;67:876.

10. Fritzemeier C, Bechthold H. Die Osteosynthese von Unter kiefergelenkfortsatzfrakturen mit alleinigen Zugang von intraoral. Dtsch Z Mund Kiefer Gesichtschir. 1993;17:66-8. 
11. Mokros S, Erle A. Transoral miniplate osteosynthesis of mandibular condyle fractures-optimizing the surgical method. Fortschr Kiefer Gesichtschir. 1996;41:136-8.

12. Veras RB, Kriwalsky MS, Eckert AW, Schubert J, Maurer P. Longterm outcomes after treatment of condylar fracture by intraoral access: a functional and radiologic assessment. J Oral Maxillofac Surg. 2007;65:1470-6.

13. Jensen T, Jensen J, Nørholt SE, Dahl M, Lenk-Hansen L, Svensson P. Open reduction and rigid internal fixation of mandibular condylar fractures by an intraoral approach: a longterm follow-up study of 15 patients. J Oral Maxillofac Surg. 2006;64:1771-9.
14. Schneider M, Lauer G, Eckelt U. Surgical treatment of fractures of the mandibular condyle: a comparison of long-term results following different approaches-functional, axiographical, and radiological findings. J Craniomaxillofac Surg. 2007;35:151-60.

15. Schramm A, Wilde F. Computer-assisted reconstruction of the facial skeleton. HNO. 2011;59(8):800-6.

16. Wilde F, Schramm A. Intraoperative imaging in orbital and midface reconstruction. Facial Plast Surg. 2014;30(5):545-53.

Open Access This chapter is licensed under the terms of the Creative Commons Attribution 4.0 International License (http://creativecommons. org/licenses/by/4.0/), which permits use, sharing, adaptation, distribution and reproduction in any medium or format, as long as you give appropriate credit to the original author(s) and the source, provide a link to the Creative Commons license and indicate if changes were made.

The images or other third party material in this chapter are included in the chapter's Creative Commons license, unless indicated otherwise in a credit line to the material. If material is not included in the chapter's Creative Commons license and your intended use is not permitted by statutory regulation or exceeds the permitted use, you will need to obtain permission directly from the copyright holder. 